\title{
The Elicitation of Verbal Humor in Total Women: Conversational Implicature and Relevance
}

\author{
Rongbin Wang ${ }^{1} \&$ Yaoqin Xue ${ }^{1}$ \\ ${ }^{1}$ School of Foreign Languages, Shanxi University, Taiyuan, China \\ Correspondence: Rongbin Wang, School of Foreign Languages, Shanxi University, Taiyuan 030006, China. Tel: \\ 86-0351-701-0644. E-mail: wangrongbin@sxu.edu.cn
}

$\begin{array}{ll}\text { Received: September 13, } 2017 & \text { Accepted: June 22, } 2018 \quad \text { Online Published: July 28, } 2018 \\ \text { doi:10.5539/ijel.v8n6p61 } & \text { URL: https://doi.org/10.5539/ijel.v8n6p61 }\end{array}$

\begin{abstract}
This research examines how conversational implicature and relevance in communication contribute to the elicitation of verbal humor in Total Women, and it discusses whether the pragmatic theoretical analysis of verbal humor can eventually be induced to a hierarchical two-stage processing like Incongruity-resolution. It is shown that (1) The dòu gén (fun-making character) Fannie's statements which flouted different maxims of conversation all built up and led to the elicitation of verbal humor; (2) Relevance-eliciting verbal humor resembled to Incongruity-resolution with the oppositeness between the first interpretation and the retrieved one communicating the presumption of optimal relevance on the one hand and the humorous inference on the other hand.
\end{abstract}

Keywords: verbal humor, elicitation, conversational implicature, relevance, incongruity

\section{Introduction}

Total Women is a stage play composed by the famous playwright Lai Shengchuan. It was set in an annual commercial appreciation banquet titled Total Woman's Night, at which Fannie (the dòu gén, the fun-making character) and Annie, Betty (the two pěng gén, who help the dòu gén make the audience laugh) held a series of humorous conversation on hot female issues. Its abundance of verbal humor made it a great success. In a broad sense, verbal humor, also called verbally expressed humor (Graeme, 2004, p. 13), includes different kinds of laughter such as comedy, irony, jokes, puns, teasing, sarcasm, satires and wordplay, etc., which are covered uniformly under humor in this research. Humor has attracted scholars' attention in various fields. Traditionally, classical theories of humor are divided into three branches: theories of Superiority, of Incongruity and of Relief theory (Arvo Krikmann, 2006, p. 33), among which the incongruity theory is the most influential cognitive interpretation of verbal humor. The Incongruity-Resolution Model (Suls, 1977) views the elicitation of humor as a result of problem-solving with incongruity being a conflict between what is expected and what actually occurs that one experiences when he comes across a verbal humor. This is done by a two-stage process in which an initial incongruity is created, and then some further information causes the resolution of that incongruity (Graeme, 2004, p. 54). In the linguistic field, scholars such as Victor Raskin (1984, p. 99) and Salvatore Attardo (2001, p. 22) tried to build up a universal model for the elicitation of verbal humor from semantic perspective. However, although there are attempts that tried to investigate the verbal humor elicitation from pragmatic disciplines, most researchers have only employed canned jokes rather than a complete corpus like the script of Total Women. In order to make a systematic analysis of the quasi comedic discourse under the guidance of pragmatic disciplines, this research will on the one hand explore how conversational implicature and relevance in communication contribute to the elicitation of verbal humor in Total Women, and on the other hand examine whether the pragmatic theoretical analysis of verbal humor can eventually be induced to a hierarchical two-stage processing like Incongruity-resolution and search for a connection of two-stage processing like Incongruity-resolution theory with pragmatic theoretical analysis.

\section{Conversational Implicature and Relevance in Communication}

\subsection{Cooperative Principle and Conversational Implicature}

Cooperative Principle brought forward by Grice on the basis of his William James lectures at Harvard in 1967 is a theory about how people use language (Levinson, 1983, p. 101). Grice suggested that in order to achieve 
rational interaction in communication, there is an underlying principle that participants would follow during interactions so as to communicate effectively and successfully. Grice called it Cooperative Principle and identifies one overall principle and four basic maxims of conversation which is expressed as follows:

\section{The Cooperative Principle}

Make your conversational contribution such as is required, at the stage at which it occurs, by the accepted purpose or direction of the talk exchange in which you are engaged.

\section{The maxims of conversation}

Quality: Try to make your contribution one that is true

i. Do not say what you believe to be false

ii. Do not say that for which you lack adequate evidence

\section{Quantity:}

i. Make your contribution as informative as is required (for the current purpose of the exchange)

ii. Do not make your contribution more informative than is required

Relation: Be relevant

Manner: Be perspicuous

i. Avoid obscurity of expression

ii. Avoid ambiguity

iii. Be brief (avoid unnecessary prolixity)

iv. Be orderly

Grice (1975, pp. 41-58)

Although the terms "principle" and "maxim" are employed, it should not be presumed that the Cooperative Principle and its maxims and sub-maxims will be followed all the time. A speaker does not always follow the maxims. If he does, he or she will communicate effectively and clearly, which Raskin (1984) defined as a bona-fide type of communication. If not, he or she may breach the maxims, which is regarded as non-bona-fide mode of communication. For Grice, if a speaker flouts the maxims ostentatiously, he or she is aware of the Cooperative Principle. He or she flouts the maxim in order to convey extra message that is unsaid, i.e. the conversational implicature (specifically particularized conversational implicature), to his or her interlocutor. And the corresponding interlocutor would believe that the speaker is still following the Cooperative Principle and therefore will endeavor to find the inferences on the basis of linguistic or situational context. But for Raskin, bona-fide communication cannot be directly analyzed by virtue of Cooperative Principle.

Therefore, it's necessary to argue for the appropriateness of analyzing the script of Total Women by virtue from the perspective of Cooperative Principle. On the one hand, the script is a naturally occurred conversation in the dramatic personae's eyes. The two pěng gén Annie and Betty are trying to communicate effectively with Fannie in the commercial appreciation banquet. In other words, the script is communicative for the dramatic personae themselves; it is bona-fide conversation. On the other hand, the audience is the indirect interlocutor and a spectator of the whole show. A dramatic persona does convey a conversational implicature to other dramatic personae when she flouts the maxims of cooperative principle. But more importantly, it is believed that she is implying a humorous effect to the audience, which to a certain extent is the original and substantial intention why the script is composed to include some pairs of conversations where there is the dramatic personae's flouting of the maxims of Cooperative Principle. Therefore, considering that the script is relatively more communicative for the dramatic personae on one hand and humorously implicative for the audience on the other hand, it is more appropriate to employ the term flout rather than violate in later discussion. Instances followed will make this clearer.

\subsection{Relevance in Communication}

Since Grice proposed his theory of conversation, i.e. Cooperative Principle, there have been continuously different scholars who endeavored to revise, reinterpret or even reconstruct the theory. While some tried to further specify its sub-maxims, others attempted to reduce its constituent maxims and sub-maxims. Among the latter, there are scholars such as Horn, Harnish, Levinson, etc. Sperber and Wilson also suggested a revision of Cooperative Principle---Relevance theory (Sperber \& Wilson, 1986), which can be regarded as both a reaction against, and a development of, the classical Gricean pragmatic theory (Huang Yan, 2007, p. 181). They proposed that communication should be relevance-oriented and relevance be the basic principle of communication; while 
Grice focused mainly on "what is unsaid", that is, conversational implicature and neglected "what is said", Sperber and Wilson drew also adequate attention to the latter. The essential idea of Relevance theory is that communication is to pursue optimal relevance, which is reflected in two sides, cognitive principle of relevance ("Human cognition tends to be geared to the maximization of relevance") and communicative principle of relevance ("every ostensive stimulus conveys a presumption of its own optimal relevance") (Sperber \& Wilson, 1995, p. 260). According to Sperber and Wilson, relevance is a function of two factors: cognitive effects and processing effort. That is, relevance is measured by cognitive effects a certain piece of information has on the hearer and the processing effort the hearer makes in order to interpret or comprehend the information. The more cognitive effects it has, the more relevant it is; the less processing effort it needs, the more relevant it is. According to Relevance theory, a certain utterance has more than one interpretation. Not all these interpretations occur to the addressee simultaneously; some are easier to be thought of. But as long as the addressee has found an interpretation that balances the cognitive effect and processing effort, he or she will stop.

\section{Pragmatic Analysis of the Elicitation of Verbal Humor in Total Women}

\subsection{Conversational Implicature as Elicited Verbal Humor}

First of all, how verbal humor is elicited as a result of violation of the maxims of Cooperative Principle will be examined.

\section{(1) Elicitation of verbal humor by flouting the maxim of Quality}

The maxim of Quality tells that people should not say what is false and what they are not sure of. But even in daily interaction, it's common to find that people sometimes offer incorrect information or messages that they lack evidence. Take the following conversation between two friends who are talking about the shared friend Tom as an instance:

\section{A: What do you think of Tom? \\ B: He is a man of his word. He always tells me that he will pay me back soon.}

It is obvious the speaker B replied A with a false piece of information for a man who was reluctant to pay back other's money could not be regarded as being faithful. By flouting the maxim of quality, the person B had achieved his communicative purpose and successfully implied that Tom was a man who usually broke his promise.

However, it is a different picture when it comes to the flouting of the maxim of Quality in a humorous script like the corpus Total Women. For example, in the prologue, Annie and Betty were very surprised when uninvited Fannie first showed herself on the stage, rather than her Grandma Zhou who was invited ahead of time:

\section{Case 1:}

Fannie: Thank you...My grandma is rather old. Thank you for especially inviting her to this banquet. She is extremely honored but she has something to deal with and is extremely sorry for not coming. All through her life my grandma never broke a promise. She was actually looking forward to this banquet, but it's really because she has some emergency to deal with. She especially wants me to express her apology to you.

Betty: What's your grandma's matter?

Annie: What's wrong?

Fannie: She passed away.

Annie: Come on! It can't be true!

Fannie: Restrain your grief, restrain your grief.

Annie: What to do with the banquet?

Fannie: Well, the banquet, that's your worry. Ease, my grandma advised me how to handle the banquet, before she went out.

Betty: Went out? Where to?

Fannie: Where else can she go? She went to heaven!

At the beginning of the prologue, Fannie confided that her grandmother was not able to attend the party simply because she had met an unexpected matter. But later she modified her remark to say that her grandmother had an emergency and passed away. Yet again, when Annie and Betty felt worried about how to handle a party without an honored guest, Fannie consoled them by saying that ease, my grandma advised me how to handle the banquet 
before she went out. Actually, Fannie was quite aware of her Grandma Zhou's death long before she came to this banquet. But since it was her first time to perform in front of so large a group of audience, she behaved so nervous on the stage that she flouted the maxim of Quality three times by falsely mentioning that my grandmother was just out. She was so embarrassed that her words were lack of logic. The flouting of the maxim of Quality elicited great humor because it conversationally implicated: she didn't even realize her mistake and did not even feel grieved at the end of this conversation. What's equally ridiculous was Annie and Betty's reaction to the news of Grandma Zhou's death: they seemed not to be sympathetic toward Fannie's sadness at all. What they cared was just the smooth organization of the banquet.

\section{(2) Elicitation of verbal humor by flouting the maxim of Quantity}

Grice $(1975,1989)$ exemplified how people might flout the maxim of Quantity in naturally occurred interaction. In that example, a student $\mathrm{X}$ who was applying for a lectureship in philosophy troubled his former teacher to write a reference letter for him. And the letter read like this:

"Dear Sir, Mr. X's command of English is excellent and his attendance at tutorials has been regular. Yours, etc."

(Grice, 1989, p. 33)

Grice further commented that "A cannot be opting out, since if he wished to be uncooperative, why write at all? He cannot be unable, through ignorance, to say more, since the man is his pupil; moreover, he knows that more information than this is wanted. He must, therefore, be wishing to impart information that he is reluctant to write down. This supposition is tenable only on the assumption that he thinks Mr. X is no good at philosophy. This, then, is what he is implicating." (Hu, 2001, p. 255). The professor flouted the maxim of Quantity by offering less information than was required. Similar case is rare in Total Women. But the flouting of the maxim of Quantity by offering more information is reflected to its full sense in many plots of the play. Take the plot Shouting abuses in the street for instance:

\section{Case 2:}

Annie: May I ask about what your grandma shouted abuses in the street?

Fannie: Shouted abuses in the street, as its name tells, my grandma began with criticizing the street and road construction. (Intimate her grandma) Why are there even more constructional pits in the street just overnight? Wasn't it just yesterday morning when the road was made? What? This time it was excavated by the Office of Telecommunications? Don't we ordinary people need to live a life? Last time the excavation took half a month. Finally, the hole was filled, but who could imagine that the diggers of water-supply company came right after? The water-supply digging took a long period of three months after which came the gas company! Another half-a-year digging! Eventually the construction by the gas company was over. But the Office of the Park Street Lighting Management came to dig! Another repetition of digging and filling! And then came the Power Grid! This time workers dug and broke all the pipes and lines of other companies! So, all the companies all came back and began to re-dig, re-dig and re-dig for a decade! Then I thought it should be an end and I could finally take a breath of my life. But no! It's time to dig for subways! This time the digging was even stronger and wider and took much longer time! Three years of digging! All those six companies, did you on earth have a connection with one another? Even not, shouldn't you have connected with one another ahead of time so as to choose a "white day" to dig together and fill the holes together? By doing so, you don't bother to install small ditch covers one by one, just install an enormous one! Even the thief cannot steal it!

In this case, Annie only asked about the overall content of Grandma Zhou's shouting abuses in the street. She did not expect a vivid imitation of Zhou's criticizing the poor transportation in Taipei. Obviously, Fannie flouted the maxim of Quantity by offering more information than Annie required. It was nothing but this detailed sarcasm that conversationally implicated Zhou's dissatisfaction of inconvenience brought about by the low efficiency of the governmental administration. This was also resonated in the audience's mind: Zhou pointed out what the ordinary people were dissatisfied with by virtue of a simple and direct criticizing. However, this was just a prelude. Fannie continued to intimate her grandmother:

\section{Case 3:}

Fannie: Isn't it said that now men and women share equal rights? Good, women now can have jobs and earn money! I heard that it was equal pay for equal work? How wonderful this is! However, why is it the case that my neighbor Mama Qian still has to do as much kitchen work as before, has to take care of children as often as before, has to mop the floor as hard as before, and has to clean the toilet as frequent as before? You see, a woman has to do her job in the meantime, has to give birth to baby. But before the delivery, a woman must ask for the maternity leave when the male manager frowns at the request as if the woman were asking for a very 
disgusting leave. Not until my age now do I realize that we women are not pregnant with a baby in our bellies, but with a disease!

Annie: What a powerful criticizing! You grandma is exactly the person who speaks for the people!

In this case, Fannie gave a long criticizing about unfair treatment and great pressure women like her neighbor Mama Qian are faced with, which further showed Zhou's so-called master craftsmanship. Just as Annie said, Zhou behaved as the mouthpiece of the people and her criticizing, though redundant, was not unpleasant to hear at all. On the contrary, her words engendered a pleasure sense of happiness. And it was no other than this consciously-offered redundant information that elicited great humor.

\section{(3) Elicitation of verbal humor by flouting the maxim of Manner}

The maxim of Manner tells that speakers should be brief and not be deliberately obscure or ambiguous. The examples of "I-C-E C-R-E-A-M-S", "Never seek to tell my love, love that never told can be" given by Grice illustrated that people may violate the maxim of Manner by saying obscurely or ambiguously. This is true for Fannie who was a bit nervous to talk in front of large audiences for the first time; thus, her words lacked logic at the beginning of the show. She talked in such an obscure way that both Annie and Betty were puzzled by her narration. Such cases are found in the plot My aunt which is excerpted as follows:

\section{Case 4:}

Betty: Every family would love to live a happy life but every family has a skeleton in the cupboard. For me, my problem is that I have an aunt who visits me every month.

Annie: By "aunt", are you saying this as a metaphor?

Betty: No, I'm not. She is really my aunt, one of my relatives.

Annie: What does she come for every month?

Betty: Nothing special, she just stays for a couple of days. And she never chooses good time. She just shows up whenever she likes to. She comes when I am working; she comes when I am jogging; sometimes she comes even in the midnight! And in a few days, she will leave without a notice! I was extremely nervous when my aunt didn't come one month. I looked for her here and there desperately. But I could find her nowhere. I could do nothing but wait for her to come. Well, my conscience told me that I did not treat my aunt well. I cursed her behind her back; I said things bad about her. I supposed that she must have known this and this was why she decided to revenge! Once I had a boyfriend. Even my mom was okay with our relation, my aunt strongly disagreed and made no effort to split the boy from me. I was rather awkward between them. From then on, I learned a lesson that I must always respect my aunt!

In this segment, Betty was encouraged to talk about a special topic referring particularly to women, that is, women's menstrual period. But she seemed to be too shy to mention it straightly in front of both male and female audience. Therefore, she chose the form of address "my aunt" which is a Chinese euphemism for female's physical menses. Even so, she was not yet at home enough to talk about her so-called aunt openhandedly. Repeatedly she just replied to Annie that I have an aunt, she was just my aunt, I'm not familiar to my aunt, etc. Moreover, Fannie described so genuinely how her so-called aunt was like, how her aunt would object her romance, etc. that as if she did have such an aunt in her real life. But of course, this was not true. The truth is that in order to avoid embarrassment, Fannie flouted the maxim of Manner by offering both obscure and ambiguous information. While these pieces of ambiguous information conversationally implicated that life was much more challenging for female than for male, Fannie's sort of absurd ways of narration tickled the audience and elicited verbal humor.

Lastly, the maxim of Relation will not be discussed in detail here. The next section is about nothing but the further development of Grice's Cooperative Principle, which is exactly related to relevance.

\subsection{Elicitation of Verbal Humor from Searching for Optimal Relevance}

In the past decades, many scholars employed Relevance theory to explain humor interpretation among whom, Yus (2003) presented a relatively general relevance-theoretic approach to humor that can be applied to all kinds of humor. Sperber and Wilson (1985) who disapproved Grice's idea of violation and proposed that whatever a speaker ostensively said, he or she said it in order to convey informative intention. Similarly, Yus held the view that joke-tellers don't violate the principle of relevance. Rather, a speaker leads his or her hearer to select a first accessible interpretation consistent with Relevance theory, only to invalidate it later with a more unlikely, but eventually correct interpretation. He further explained that if the utterance is not as informative as required, irrelevant, untrue, etc., a search for a "more relevant interpretation worth being processed may be activated, 
despite the supplementary mental effort required. Humorous effects such as the enjoyment in the resolution of incongruity are worth this extra cognitive effort (Yus, 2003, pp. 1295-1331). As can be seen, his proposal not only applies Relevance theory to humor without mentioning violation of the principle, but also follows the Incongruity-resolution model to a certain extent.

Now let us turn to examine how Relevance theory works in the interpretation of the verbal humor elicitation in Total Women. First, let's take a look at some cases of verbal humor which can be well explained by relevance in the excerpt of Romantic Disease:

\section{Case 5:}

Fannie: You are infected by the disease of romance!

Betty: The disease of romance? How is it possible that romance is a disease? From ancient time to modern ages, what all of those famous poets sang the praise of was nothing but exactly romance. Take William Shakespeare for example, his poems are the most positive ones just like the following lines from his sonnets: Shall I compare thee to a Summers day? Thou art more lovely and more temperate.

Fannie: All those famous poets have made an innate mistake. Human-beings are solid but summer days are gas. How ridiculous is it to compare a solid to gas?

Assumption from Betty's words: Love poems written by Shakespeare like "shall I compare thee to the summer day?" shows that romance is like a bed of roses rather than a disease (accessible from the processing of what Betty said).

Assumption from Fannie's words: Poets who wrote love poems like "shall I compare thee to the summer day?" must be infected by the so-called "disease of romance" (accessible from the processing of what Fannie said).

Resolution of the clash: Love is as "awesome" as sickness.

Annie was not convinced by Fannie's words. Thus, she came out another line of Shakespeare's poems:

\section{Case 6:}

Annie: How about the following lines from the poet Shakespeare? And therefore, from my face she turns my foes, that they elsewhére might dart their injuries. Yet do not so, but since I am near slain, kill me outright with looks, and rid my pain.

Fannie: The sickness is obvious! You see, when talking about romance, Shakespeare is either talking either about pain or about struggling, either about hesitation or about tears. What's the difference is this from a disease?

Assumption from Annie's words: Shakespeare couldn't have been infected by the so-called "romantic disease" (accessible from Annie's words)

Assumption from Fannie's words: Those poets are no other than prisoners of love (accessible from Fannie's cogent debate).

Resolution of the clash: Love is blind. One cannot love and be wise.

Fannie further pointed out that besides poems, popular songs are more infective than poems:

\section{Case 7:}

Annie: You mean even those popular songs have similar problem?

Fannie: Yes, big problem! And what extremely wrong are those songs that are distorted.

Betty: How about this great song? There is definitely no problem with it. (singer Wang Fei's song) I am willing to be exiled to the frontier, I am willing to be exiled to the frontier, for you, for you...

Annie \& Betty: For you, for you...

Fannie: You ask what's the problem of the song? It's obsessive-compulsive disorder! A very severe disease!

Annie: How about this song? (Sing) Please think of this, please have a look at this, that the moon stands for my heart!

Fannie: This song is by no means a romantic song! It's a song for ending romance! The song keeps telling you to think of that, to have a look at that, that the cold stone hang far in the outer space stands for his heart! He has long been cold-hearted toward you and don't you listen through lines? 
Assumption from Annie \& Betty's words: Love song is symbol of romance. It describes how selfless females in love are (accessible from Annie and Betty's sung lyrics).

Assumption from Fannie's words: Love song can better portray the similarity of romance and disease (accessible from Fannie's words such as obsessive-compulsive disorder, distortion of symbolic meaning of the moon).

Resolution of the clash: Women in love in no case are sane and sensible.

According to Yus (2003, p. 1313), incongruity is not sufficient for the creation of humor. He further pointed out three fundamental elements that are beneficial in humor creation. They are:

a. the actual resolution of incongruous ongoing interpretations;

b. the realization of having been fooled by the communicator;

c. a positive interaction of the joke with the addressee's cognitive environment.

Specifically speaking, if Case 5 to Case 7 are to be humorous, there are some extra conditions. To begin with, the incongruity brought about by the disagreement of Fannie on one hand and Annie and Betty on the other hand on the essence of romance must be resolved by their verbal dispute. Secondly, the audience should realize that they have been fooled and accept this not-unpleasant way of being fooled, when they find that the first interpretation (in these three cases, it refers to Annie or Betty's positive argument for love) they have accepted is less cogent and less persuasive than Fannie's words, that is, the second interpretation of love. Additionally, the audience's being ready to accept Fannie's extraordinary opinion of romance, love poems and love songs despite their traditional view of romance is also a must for the humor elicitation. Then what's the relation between optimal relevance and the utterances of verbal humor? Generally speaking, communication is to achieve optimal relevance. But it is a more complicated case for verbal humor. On the one hand, relevance is still basic for verbal humor. On the other hand, the utterances of verbal humor do not simply pursue for optimal relevance. Rather, humorous effect on the interlocutor gets the priority. Consequently, for those cases of verbal humor which can be well explained by relevance, the "first interpretation" or assumption is not the communicator's intentionally conveyed information. Nor is the retrieved interpretation or assumption, which, although mostly call for a relatively larger cognitive effort than an ordinary non-humorous narration. On the contrary, it is the abrupt oppositeness between the first interpretation and the retrieved one that is the communicator's intended information. And this information, once it has elicited a humorous effect on the interlocutor, can be said to have been successfully expressed. Although in such cases more effort is made, more effect is achieved correspondingly because those utterances have not only transformed information successfully, but also, they have produced a humorous effect on the interlocutor. In other words, there is still the best balance between effort and effect. Those utterances of verbal humor which can be well explained by relevance also communicate the presumption of their optimal relevance.

\subsection{Further Discussion}

Two points should be further emphasized about conversational implicature as elicited verbal humor. One is that before doing any specific case analysis, researchers must first of all argue for the appropriateness of analyzing humorous texts like Total Women by virtue of Cooperative Principle. Secondly, it's exactly the conversational implicatures resulting from flouting sub-maxims of Cooperative Principle that can make the scripts laughable. Down to details in case studies 1 to 4, the dòu gén Fannie's self-contradictory statement which flouted the maxim of Quality, her much more redundant information which flouted the maxim of Quantity, her obscure and ambiguous way of story-telling which flouted the maxim of Manner etc. all contributed to humor elicitation. However, as is shown above, the process of humor elicitation resulted from flouting of maxims of Cooperative Principle is not a two-stage process like the Incongruity-Resolution model.

As for the elicitation of verbal humor through searching for optimal relevance, we may easily find its inequality to its Cooperative Principle. As is revealed in 3.3, a relevance theoretical account for humor elicitation treats it as a two-stage process, specifically, Annie or Betty on the one hand led the audience to select a first interpretation consistent with Relevance theory, but later Fannie on the other hand invalidated it with a second interpretation. In other words, relevance-theoretic approach to verbal humor resembled more to Incongruity-resolution and simultaneously emphasized the abrupt oppositeness between the first interpretation and the retrieved one. This oppositeness, though sometimes calling for extra effort, still produced a best balance between effort and effect, thus elicited humor by way of communicating the presumption of their optimal relevance. 


\section{Conclusion}

This paper provides a series of case studies of the elicitation of verbal humor in Total Women from pragmatic disciplines. As is illustrated, conversational implicatures resulted from flouting of different submaxims of Cooperative Principle are often humor-loaded, which makes the conversational implicature one of the main sources of humor elicitation in Total Women. It is also revealed that the eliciting process of conversational implicature as humor is not a two-stage process, but to understand the verbal humor related to relevance requires a two-step analysis of the first interpretation and the retrieved interpretation, and the sharp incongruity between them. And it is the abrupt oppositeness between these two interpretation that leads to the elicitation of verbal humor in the meantime communicating the presumption of the optimal relevance. These findings show that verbal humor can be elicited through different linguistic resources on the one hand and on the other hand the eliciting processes differ correspondingly, one implication for the designing of dramatic plots such as a comedic script, if to make the script elicit as much verbal humor as possible, needs to take different pragmatic disciplines into consideration, pay especial attention to the differences in eliciting mechanisms and in the linguistic realizations, and scientifically design conversations that reflect such differences.

\section{Acknowledgement}

This study is supported by the 2018 National Social Science Fund of China (18CYY022), 2017 Shanxi Provincial Educational Reform Project (J2017009), 2016 University Philosophical and Social Science Project of Shanxi Province (2016216), and the National Scientific Project of University Foreign Language Teaching (01050216030019).

\section{References}

Arvo, K. (2006). Contemporary linguistic theories of humor. Folklore, 33, 27-58.

Attardo, S. (2001). Humorous Texts: A Semantic and Pragmatic Analysis. New York: Mouton de Gruyter. https://doi.org/10.1515/9783110887969

Graeme, R. (2004). The Linguistic Analysis of Jokes. London: Routledge.

Grice, H. P. (1975), Logic and Conversation. In J. Morgan \& P. Cole (Eds.), Syntax and Semantics 3: Speech Acts (pp. 41-58). New York: Academic Press.

Hu, Z. L. (2001). Linguistics: A Course Book. Beijing: Peking University Press.

Huang, Y. (2007). Pragmatics. London: Oxford University Press.

Levinson, S. C. (1983). Pragmatics. Oxford: Cambridge University. https://doi.org/10.1017/CBO9780511813313

Raskin, V. (1984). Semantic Mechanisms of Humor. Dordrecht: D. Reidel Publishing Company. https://doi.org/10.1007/978-94-009-6472-3

Sperber, D., \& Wilson, D. (1986). Relevance: Communication and Cognition. London/Cambridge: Harvard University Press.

Sperber, D., \& Wilson, D. (1995). Relevance: Communication and Cognition (2nd ed.). Oxford: Blackwell.

Suls, J. (1977). Cognitive and disparagement theories of humor: a theoretical and empirical synthesis. In A. J. Chapman \& H. C. Foot (Eds.), It's a Funny Thing, Humor (pp. 41-45). Oxford: Pergamon Press. https://doi.org/10.1016/B978-0-08-021376-7.50012-7

Yus, F. (2003). Humor and the search for relevance. Journal of Pragmatics, 35, 1295-1331. https://doi.org/10.1016/S0378-2166(02)00179-0

\section{Copyrights}

Copyright for this article is retained by the author, with first publication rights granted to the journal.

This is an open-access article distributed under the terms and conditions of the Creative Commons Attribution license (http://creativecommons.org/licenses/by/4.0/). 